University of South Carolina

Scholar Commons

$1-1999$

\title{
Effects of Direct Instruction and Environmentally Designed Instruction on the Process and Product Characteristics of a Fundamental Skill
}

Terry Sweeting

California State University - Northridge

Judith E. Rink

University of South Carolina - Columbia, jrink@mailbox.sc.edu

Follow this and additional works at: https://scholarcommons.sc.edu/pedu_facpub

Part of the Education Commons

Publication Info

Published in Journal of Teaching in Physical Education, Volume 18, Issue 2, 1999, pages 216-233.

http://journals.humankinetics.com/jtpe-contents

(c) 1999 by Human Kinetics Publishers, Inc.

This Article is brought to you by the Physical Education, Department of at Scholar Commons. It has been accepted for inclusion in Faculty Publications by an authorized administrator of Scholar Commons. For more information, please contact digres@mailbox.sc.edu. 


\title{
Effects of Direct Instruction and Environmentally Designed Instruction on the Process and Product Characteristics of a Fundamental Skill
}

\author{
Terry Sweeting \\ California State University-Northridge \\ Judith E. Rink \\ University of South Carolina
}

\begin{abstract}
This study investigated the effects of direct instruction and an environmentally designed instructional strategy on the product and process characteristics of kindergarten and second grade children in the standing long jump. One hundred and sixteen kindergarten and second grade students participated in the study and were assigned to a 3-day, 60-trial, direct instruction group or a 3-day, 60-trial, environmentally designed instruction group. A pretest, posttest, and retention test were administered in a flat mat testing condition and one designed to elicit performance through the testing environment (the swamp). Both instructional intervention groups were different from the control group at the posttest and the retention test. Younger students, less skilled students, and students tested at the pretest benefited most from the environmental testing condition. With age, skill, and experience the environmental testing condition lost its advantage. The instructional interventions had different effects on the process characteristics of the jump.
\end{abstract}

A major outcome of physical education programs should be the development of motor skills (NASPE, 1992, 1995). Of particular concern for the elementary physical educator is the development of fundamental motor skills such as running, jumping, throwing, and so on, which are thought to form a foundation for the acquisition of more complex specialized skills.

Inherent in our concept of skillful performance of motor skills is the notion that the effective pattern (the accurate or forceful throw, or the high or long jump) is achieved through the acquisition of mature movement process characteristics usually taught for as good form. The assumption is that the student who does the movement in a mature way will be more effective when force production is a critical determinant of success. While it is recognized that "mature form" is not always an appropriate response for all situations (e.g., throwing at a close distance), the skilled performer has available the appropriate response for all task

T. Sweeting is with the Department of Kinesiology at California State UniversityNorthridge, 91330. J.E. Rink is with the Department of Physical Education at the University of South Carolina, Columbia, SC 29208. 
situations. The unskilled, (most often) young child is often unable to produce an appropriate pattern when maximum force production is the appropriate response.

For several fundamental patterns, developmental sequences chronologically describing the stages of acquisition of mature patterns used for maximum force production have been developed and, in the case of the overhand throw pattern, have been validated (Roberton, 1978). Although it is well accepted that children acquire fundamental motor patterns incrementally with age and experience (Roberton \& Halverson, 1984), teachers are involved in the process of finding ways to design experiences that will help children acquire more mature and effective patterns as part of an instructional physical education program.

From a motor control perspective, dynamical systems theory (Kugler, Kelso, \& Turvey, 1980; Newell, 1986) suggests that the patterns of coordination exhibited by individuals emerge from the interaction of organismic (person), environmental, and task constraints. "The dynamic state of the motor control system interacts with the perceptual and motor variables to produce patterns of movement appropriate for achieving the action goal of the situation" (Magill, 1998, p. 51). The established and stable patterns of coordination for the young child may not be effective for tasks that require high levels of force production. From this perspective instruction in motor skills becomes an intervention designed to change the existing pattern used by the young students to a more effective pattern for a given task situation (i.e., maximum force).

During instruction the task constraints may be manipulated in several ways to enhance or elicit more mature patterns of coordination. Additional information about the task (i.e., verbal cues, demonstration) may be provided by the teacher via direct instruction. The teacher may also change the physical arrangements for the task to elicit the pattern of coordination desired. This is usually referred to as environmental design (Rink, 1998). Environmental design is usually used by a teacher to manipulate the task conditions to both change the student's perception of the action goal (i.e., what they are trying to do in the task) as well as to constrain environmentally the action in a manner that encourages the student to "self organize" a more mature pattern (i.e., jump to the furthest color line you can).

Research has been done both in direct instruction and environmental design. From a pedagogical research perspective, there is more than ample support for the use of direct instruction to develop motor skills (French et al., 1991; French, Rink, \& Werner, 1990; Gusthart \& Springings, 1989; Metzler, 1989; Rink, French, Werner, Lynn, \& Mays, 1992; Silverman, 1991; Werner \& Rink, 1989). Direct instruction usually involves the selection of clear instructional goals, step by step hierarchical sequenced chunks of content, high teacher centered structure, and immediate specific feedback on performance. To teach a motor skill directly, the teacher would carefully order a sequence of learning experiences that would lead the learner from where he or she is in performance to mature form and the effective use of a pattern. Not as common as direct instruction is the idea of environmentally designed instruction in which the teacher attempts to design the environment to elicit good performance in a motor skill without necessarily focusing the learner cognitively on the movement process characteristics inherent in that performance. Research has documented both the positive and negative effects of varying environmental conditions on the movement performance of young children (e.g., Belka, 1985; Isaacs, 1980; Mallais, 1984; Morris, 1976; Strohmeyer, Williams, \& Schaub-George, 1991), but instructional textbooks have only alluded to the idea of using environmental design as an instructional strategy to bring out more effective and efficient movement patterns of young children 
(Herkowitz 1978; Logsdon et al., 1984; Rink, 1998; Siedentop, Herkowitz, \& Rink, 1984).

Previous studies in the area of environmental conditions have been short term and have generally used only product measures or achievement scores to ascertain the influence of task conditions on motor performance (Belka, 1985; Isaacs, 1980; Williams \& Shaub-George, 1991). Achievement scores do not always directly reflect movement content changes and may mask the effects of certain environmental factors on learning motor skills, particularly with young children who may be at early stages of development in the acquisition of a skill. The laboratory setting in which most of the research has been performed also reduces the generalizability of the information to the educational setting because of ecological validity issues. Most studies investigating the effects of environmental conditions have measured only immediate effects with no measure of learning or retention of the motor skill after a period of time has elapsed, and no information on the long term and continued effects of an environmental condition on the acquisition phase of motor skill are available.

The purpose of this study was to compare the effects of a 3-day direct instruction and a 3-day environmental design instructional strategy on learning a fundamental movement pattern. The standing long jump was chosen for the study, because it is a fundamental pattern identified as being important to primary school age youth (NASPE, 1995) and because the authors considered this task to be reasonability affected by the manipulation of environmental conditions. Two different school age groups were selected for study. Kindergarten children (approximately 5 years old) were selected, because they are just at a stage where they are beginning to acquire the standing long jump. Second grade students (approximately 7 years old) were also selected, because they are assumed to be at a stage where they were capable of refining their performance to develop mature form (NASPE, 1992). Great variability within each of the age groups was anticipated.

The intent of the study was to describe both process characteristics (form) as well as product scores (distance jumped) over the 3-day instruction period. Since no fully validated developmental sequence that would provide a developmental ordering of process characteristics is currently available for this skill, the authors chose to use the developmental stages developed by Roberton and Halverson (from Payne \& Isaacs, 1991) to describe changes in process characteristics as a result of instruction. Roberton and Halverson's work is inclusive of all phases of the jump and is commonly described in the textbooks used extensively by teachers. This component analysis was used as the basis of instruction and testing.

\section{Methods}

One hundred and sixteen kindergarten and second grade students were pretested for their product scores (distance jumped in the standing long jump). Forty students from two intact kindergarten classrooms were combined and divided into two experimental groups based on their pretest scores (high skill, $>111 \mathrm{~cm}$; average skill, $77-111 \mathrm{~cm}$; low skill, $<77 \mathrm{~cm}$ ). Forty second graders from two intact Grade 2 classrooms were also combined and divided into two experimental groups based on their pretest scores (high skill, $>127 \mathrm{~cm}$; average skill, $100-127 \mathrm{~cm}$; low skill, $<110 \mathrm{~cm}$ ). A third intact kindergarten group $(n=16)$ and a third intact second grade class $(n=20)$ served as a control group. Since the control group could not be randomly divided, the decision was made to use the control group in this situation to monitor the effects of repeated 
testing and any changes in process characteristics that might occur as a result of time due to maturation. This role for a control group is consistent with research in both pedagogy as well as motor development, particularly with young children where one would expect wide variations in maturation. Participants were from an elementary school in a middle to upper socioeconomic area of Columbia, South Carolina. A parental consent form was completed for all participants in the study.

\section{Pilot Study}

A pilot study with students not in the study was conducted to determine the selection of tasks that would be used for the environmental condition. A variety of environments were designed to elicit good form in the jump. Several of the environments designed had a negative effect on good form and were discarded, such as having students jump to catch a ball suspended on a string and having students touch a bar in back of them to encourage good arm action in the preparation. As a result of the pilot test, four environmental tasks were selected for the study: a single, low hurdle placed out in front of the performer, a set of two hurdles, a series of pictures of swamp creatures such as snakes and lizards placed on the mat in front of the subject to jump over (the swamp), and a series of colored bands across the mat in front of the subjects. Each of these conditions created an environment that seemed to encourage a forceful jump for both age groups. In addition, the hurdles tended to encourage more height on the jump.

\section{Experimental Procedures}

A pretest, posttest, and retention test were administered. The pretest was administered just prior to the instructional intervention. The posttest was administered within 3 days following the end of instruction, and the retention test was administered to 75 subjects approximately 3 months after the posttest. Product scores were obtained for subjects in all three tests. Process characteristics were obtained for the pretest and posttest. Although the study would have been stronger with the addition of retention test process scores, process scores were not obtained for the retention test because of the time consuming nature of the analysis and the little difference between the posttest and retention test product scores.

In order to counteract the advantage produced by the specific instructional intervention, all subjects were pre and posttested under two counterbalanced conditions: a flat mat condition and one environmental condition (the swamp condition). The flat mat condition consisted of a 4-foot by 8 -foot gymnastics mat. The "swamp" condition included pictures depicting a swamp placed on a mat for subjects to jump over. The pictures were placed up to the mean distance for each age group (89-90 centimeters for the kindergarten students and 110-111 centimeters for the second grade students) (Clark \& Phillips, 1985). For testing purposes a marker was taped to the floor at a distance of $6 \mathrm{in}$. from the mat to create a starting line and insure measurement consistency. Two researchers were present at each mat, one to record scores and one to situate and signal the subjects when to start. Each child was given three trials at the flat mat testing station and three trials at the swamp testing station. The distance jumped was recorded in centimeters for each of the six trials.

All trials were videotaped from a side angle for analysis of the process characteristics. A slow motion video analyzer was used to code process characteristics. 
The coding was done blind to the experimental condition. All three trials for each subject's pretest and posttest were coded using the categories identified by Roberton and Halverson (1984). The description in the appendix describes this framework with the expanded descriptions of coding conventions that were used to guide the analysis.

Intra- and inter-observer reliability measures were obtained for all process data. Intra-observer reliability for the process characteristics was calculated using simple percentage of agreement for the trials of 10 subjects randomly selected from the second grade control group. The intra observer reliability ranged from $83-97 \%$ on each of the components of the jump. Inter-observer reliability measures for the nine variables were also obtained with a second observer using the trials of 10 subjects randomly selected from the kindergarten control group. Both observers practiced together using the coding form until they were consistent with each other in their observations. Practice tapes were different from those used to report reliability. Inter-observer reliability measures ranged from $70-89 \%$. The $70 \%$ reliability on a few of the observations was due to the lack of clarity in the videotape for the abduction of the arms at takeoff and effected a few of the subject's scores.

\section{Intervention}

The subjects participated in three 25-min physical education lessons during the regularly scheduled physical education period that met two times per week. The two experimental groups were taught during the same time period at different ends of the gym. The control groups received no instruction or additional practice trials in jumping. Both teachers were highly experienced elementary school physical educators. Because of the direct relationship between the number of practice trials and student learning, instruction was designed to provide approximately 20 practice trials each instructional period for a total of 60 practice trials for each instructional treatment.

Treatment protocols were designed prior to instruction and monitored by two instructional assistants. The environmental instructional group was taught exclusively using stations. Each group (kindergarten and second grade environmental design instructional group) was organized into one of four stations with five subjects at each station. One of the environmental conditions comprised each station: a single hurdle task, a double hurdle task, a colored bands distance task, and the distance "swamp" task. All tasks were made appropriate for both age levels. The single hurdle was a rolled newspaper wand resting on two plastic quart milk cartons placed on a mat $18 \mathrm{in} .(46 \mathrm{~cm})$ from the starting line. The double hurdle task consisted of a 6 -in. hurdle placed $18 \mathrm{in.}(46 \mathrm{~cm})$ from the starting line and an 8 -in. $(21 \mathrm{~cm})$ hurdle placed $12 \mathrm{in} .(31 \mathrm{~cm})$ ahead of the first hurdle. The distance bands task consisted of four colored bands placed horizontally across the mat. Some of the bands were placed beyond where it was anticipated any of the subjects could jump. The closest tape was approximately $35 \mathrm{in}$. $(89-90 \mathrm{~cm})$ for kindergarten and $43 \mathrm{in}$. (110-111 cm) for the second graders. The "swamp" condition consisted of flat discs and pictures depicting a pretend swamp to jump over. The furthest edge of the swamp measured $89-90 \mathrm{~cm}$ and $110-111 \mathrm{~cm}$ for the kindergarten and second grade respectively.

Each child in the environmental instructional group performed five practice trials at each of the four stations each day of instruction (total 20 trials each day). The tasks used for the environmental condition were not considered a progression, and therefore, groups practiced the tasks in a different order. The role of the teacher 
in the environmental instruction group was primarily organizing students for practice at each of the four stations. At no time were students given instruction or feedback on how to perform. A teacher assistant at each station assisted the teacher in monitoring the number of trials and giving students encouraging feedback only (no specific information on performance).

An experienced elementary school physical educator and university professor competent in delivering direct instruction provided the instruction for the direct instruction group that focused on demonstration and the use of summary cues for the standing long jump. On the first day of instruction, students were given an initial demonstration of the jump. They "walked through" the cues with the instructor focusing on the preparation, flight phase, and landing of the jump. The term crouch was used as a summary cue of the description and demonstration of the preparation phase of the jump, and the term explode was used for the take off. The emphasis in both phases was on the use of the arms to swing back and then thrust forward to a full "reach" at take off. Practice the first day consisted of seeing how far students could jump on a flat mat and from a line on the gym floor.

On the second day of instruction, students were shown the jump in slow motion on videotape in order to communicate the full extension at take off and the tuck in flight. The video was frozen at full extension and again at the tuck position in flight. Student practice on the second day consisted of initially practicing to get the body fully extended at take off and later focusing on the explosive nature of the action. The role of the arms in both ideas was emphasized. Feedback was provided to individual students using the cues the students were given.

On the third day, the cues for the entire movement were reviewed and students practiced for "form" on their own mats. In addition students practiced by jumping consecutively across the gym space. They were encouraged to see if they could get from one side to another in only a few jumps.

During the instruction for the direct instruction group, extension tasks (Rink, 1998) consisted primarily of self-testing tasks encouraging jumping for distance. Practice was encouraged by varying the tasks both on and off the mat such as, "See how many jumps it takes you to get across the room." Group performance was refined (Rink, 1998) each day in a manner to be congruent with the tasks given. No environmentally designed tasks were given other than the idea of jumping as far as one could on the flat mat. Feedback to individual students was given appropriate to their stage of development in the skill based on teacher observations of individual and group performance. Feedback was primarily congruent with the cues that were the focus for the task, specific to individuals, and given in the form of refining tasks to the group.

The environmental design group received exactly 20 practice trials each lesson. The number of practice trials in the direct instruction group varied slightly from subject to subject because of the nature of independent practice, with several subjects receiving slightly more than 20 practice trials and several subjects receiving slightly less than 20 practice trials. No deviations in the planned treatment were noted by the observers.

\section{Results}

Three different sets of data are presented. The first set of product scores represents the acquisition of the ability to jump for distance from the pretest to posttest. The second set of data represents changes in the process characteristics 
Table 1 Significant Changes in the Process Characteristics-Percentage of Students in Each Category by Experimental Group

\begin{tabular}{|c|c|c|c|c|c|c|}
\hline \multirow[b]{2}{*}{ Category } & \multicolumn{2}{|c|}{ Control } & \multicolumn{2}{|c|}{ Direct } & \multicolumn{2}{|c|}{ Environmental } \\
\hline & Pre & Post & Pre & Post & Pre & Post \\
\hline & \multicolumn{6}{|c|}{ Preparation Phase } \\
\hline \multicolumn{7}{|l|}{ Arms, flat mat } \\
\hline Category 1 & 15 & 15 & 32 & 6 & 23 & 16 \\
\hline Category 2 & 12 & 21 & 16 & 19 & 16 & 10 \\
\hline Category 3 & 73 & 64 & 51 & 74 & 61 & 74 \\
\hline \multicolumn{7}{|c|}{ Arms, swamp (second grade) } \\
\hline Category 1 & 24 & 6 & 7 & 0 & 7 & 7 \\
\hline Category 2 & 24 & 18 & 14 & 7 & 0 & 0 \\
\hline Category 3 & 53 & 77 & 79 & 93 & 93 & 93 \\
\hline \multicolumn{7}{|c|}{ Arms, swamp (kindergarten) } \\
\hline Category 1 & 26 & 19 & 53 & 6 & 29 & 12 \\
\hline Category 2 & 13 & 26 & 12 & 18 & 35 & 24 \\
\hline Category 3 & 63 & 56 & 35 & 77 & 35 & 65 \\
\hline & \multicolumn{6}{|c|}{ Takeoff Phase } \\
\hline \multicolumn{7}{|l|}{ Arms, swamp } \\
\hline Category 1 & - & - & - & - & - & - \\
\hline Category 2 & 33 & 40 & 10 & 16 & 35 & 10 \\
\hline Category 3 & 60 & 58 & 87 & 74 & 74 & 81 \\
\hline Category 4 & 6 & 0 & 0 & 10 & 0 & 10 \\
\hline \multicolumn{7}{|l|}{ Arms, flat mat } \\
\hline Category 1 & - & - & - & - & - & - \\
\hline Category 2 & 24 & 33 & 13 & 19 & 26 & 26 \\
\hline Category 3 & 76 & 61 & 87 & 65 & 71 & 65 \\
\hline \multirow[t]{2}{*}{ Category 4} & 0 & 0 & 0 & 13 & 0 & 10 \\
\hline & \multicolumn{6}{|c|}{ Flight Phase } \\
\hline \multicolumn{7}{|l|}{ Arms, flat mat } \\
\hline Category 1 & 24 & 36 & 13 & 19 & 26 & 26 \\
\hline Category 2 & 3 & 18 & 13 & 0 & 23 & 23 \\
\hline Category 3 & 73 & 42 & 68 & 74 & 48 & 48 \\
\hline Category 4 & 0 & 0 & 6 & 6 & 0 & 0 \\
\hline \multicolumn{7}{|l|}{ Trunk, flat mat } \\
\hline Category 1 & 9 & 24 & 12 & 10 & 12 & 12 \\
\hline Category 2 & 6 & 18 & 10 & 0 & 6 & 0 \\
\hline Category 3 & 85 & 58 & 77 & 90 & 81 & 87 \\
\hline \multicolumn{7}{|l|}{ Trunk, swamp } \\
\hline Category 1 & 15 & 24 & 16 & 3 & 19 & 10 \\
\hline Category 2 & 24 & 30 & 25 & 10 & 12 & 0 \\
\hline Category 3 & 61 & 46 & 58 & 87 & 68 & 90 \\
\hline \multicolumn{7}{|l|}{ Legs, swamp } \\
\hline Category 1 & 27 & 24 & 10 & 3 & 13 & 6 \\
\hline Category 2 & 55 & 61 & 65 & 45 & 58 & 26 \\
\hline Category 3 & 18 & 15 & 26 & 52 & 29 & 68 \\
\hline
\end{tabular}


from pretest to posttest, and the third set of data represents the analysis of the retention scores for the jump for distance.

\section{Product Scores: Acquisition of Distance Jumped}

Scores for distance jumped were averaged for the three trials to produce a mean score. Mean scores for distance jumped were analyzed in a $2 \times 3 \times 2 \times 2 \times 2$ (Age $\times$ Group $\times$ Skill Level $\times$ Testing Condition $\times$ Time) ANOVA with repeated measures on the last two factors. Significant main effects were found for age $(F[1,82]$ $=64.87, p<.01, F[2,82]=59.09, p<.01)$, testing condition $(F[1,82]=45.07, p<$ $.01)$, and time $(F[1,82]=42.20, p<.01)$. As expected, second graders (approximately 7 years old) jumped farther overall than kindergarten students. The other main effects were superseded by the presence of three significant two way interactions: Testing Condition $\times$ Age $(F[2,82]=4.20, p<.01)$, Testing Condition $\times$ Skill Level $(F[2,82]=11.77, p<.01)$, and Testing Condition $\times$ Time $(F[2,82]=7.61, p$ $<01)$. These interactions are presented graphically in Figure 1.

All three significant interactions involved differences in performance between the swamp and flat mat testing conditions. First, the impact of the swamp testing condition was greater for the kindergarten students. Five-year-olds benefited more from performing in the swamp condition. Second, low skilled students were more positively influenced by the swamp testing condition than higher skilled students. Third, differences between the two testing conditions were greater at the pretest than the posttest.

\section{Process Data: Acquisition}

Measuring change in process characteristics of movement over time is problematic. The modal category for the three jumping trials on the pretest and posttest for each process characteristic was determined and used to chart change as is consistent with motor development literature (Roberton \& Halverson, 1984). The modal category for the pretest was subtracted from the posttest modal category. The corresponding difference score indicated change in process. For example, a positive difference score indicated progression in movement form, a zero score indicated essentially no change, and a negative score indicated regression in movement process for a particular movement component.

These difference scores were analyzed by analysis of variance of ranks. First, the difference scores for each process characteristic were ranked. Separate $2 \times 3$ (Age $\times$ Group) ANOVAs were performed on the ranked scores for each process characteristic under each testing condition. The sums of squares for each main effect, the interaction, and the total sum of squares from the analyses of variance of ranks were used to construct the Puri and Sen L statistic (Hartwell \& Serlin, 1989; Sawilowsky, 1990). The Puri and Sen L statistic is a nonparametric test. Sawilowsky (1990) has shown this statistic to be more powerful and appropriate for tests of interaction than analysis of variance of ranks. The $\mathrm{L}$ statistic is distributed as a chi-square.

The presentation of the data describing changes in process characteristics is organized by the phase of the jump and the movement component presented for both the flat mat and the swamp testing condition. The tests for Age, Group, and Age $\times$ Group are essentially tests of the Age $\times$ Pre-Post, Group $\times$ Pre-Post, and Age $\times$ Group $\times$ Pre-Post interactions because the difference scores from pretest to posttest were the dependent variables. Tests indicated significant changes among 

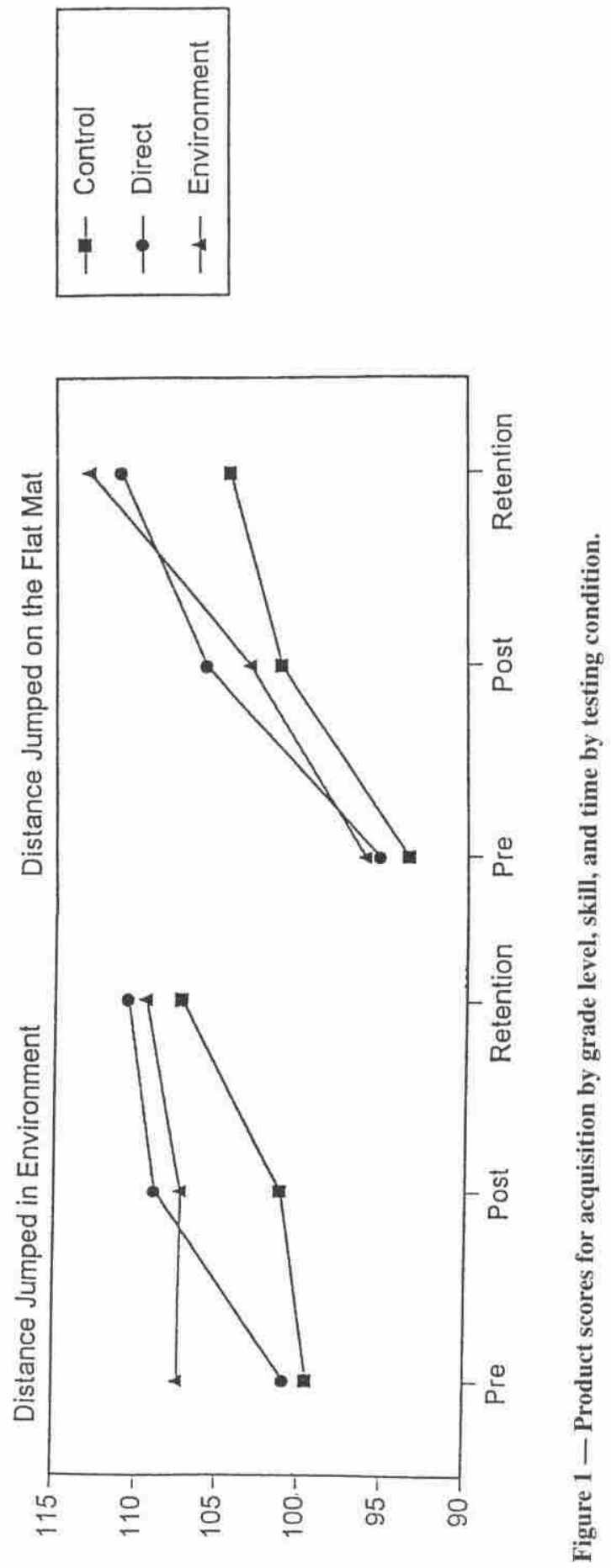
the groups for performance on the flat mat in preparation of the arms $(02[2]=$ $9.83, p<.05)$, arms at takeoff $(02[2]=6.55, p<.05)$, arms in flight $(02[2]=7.63$, $p<.05)$, and trunk in flight $(02[2]=10.96, p<.01)$. Significant effects were found for performance in the swamp testing condition as well. Group effects were found for the arms at takeoff $(02[2]=11.03, p<.01)$, the legs during flight $(02[2]=6.33$, $p<.05)$, and the trunk in flight $(02[2]=8.46, p<.05)$. The Age $\times$ Group interaction for the preparation of the arms was significant $(02[2]=7.53, p<.05)$.

The process characteristic data is presented descriptively in terms of percentages of students in each category at the pretest and the posttest for those process components where significant differences were identified. Table 1 describes the percentage of subjects identified in each category of the process characteristic instrument by age and by experimental condition for those components where there was a significant change from pretest to posttest in each phase of the jump. Higher categories of the component analysis represent more mature form. Positive differences are considered in terms of a larger percentage of students in the higher categories of the instrument and a lower percentage of students in the lower categories of the instrument. In some cases, these differences reflect differences in the testing condition (flat mat or swamp testing condition). In some cases the differences are reflective of the instructional treatment or the interaction of the instructional treatment with the testing condition.

\section{Preparation Phase of the Jump}

Changes in the preparation phase of the jump occurred primarily with the component describing the use of the arms for both testing conditions.

Flat Mat. A large percentage of the subjects in all three groups prepared for the jump by flexing their arms above their hips in the pretest (highest category). Both experimental groups moved most of their subjects to the highest category for use of the arms. The direct instruction group demonstrated the poorest performance at the pretest and the best performance in use of the arms in preparation at the posttest.

Swamp. While a majority of 7-year-olds for all of the groups were in Category 3 (arms flexed above hips) at the pretest, the control group was considerably less skilled in this component at the pretest and showed some improvement at the posttest, although still not at the levels of both experimental groups. For the kindergarten, both experimental groups improved performance for this component with the direct instruction group showing the most increase from pre to post.

\section{Takeoff Phase of the Jump}

Changes in the takeoff phase of the jump occurred primarily in the use of the arms for both the flat mat and the swamp testing condition.

Flat. In respect to the takeoff phase of the jump, most subjects began in Category 3 (arms abducted) of five categories, with some subjects in Category 2 (winging arms). While the control group regressed, the experimental groups moved some subjects to Category 4 (arms forward, partial stretch). For a few students in the direct instruction group some regression was also identified.

Swamp. At takeoff, most subjects were in Category 3 (arms abducted) for this component. While the control group showed some regression both experimental groups demonstrated some improvement and moved some subjects to Category 4 (arms forward, partial stretch). 


\section{Flight Phase of the Jump}

Significant changes in the arms and trunk were identified for the flight phase of the jump when tested on the flat mat. For the swamp condition significant changes for the trunk and legs were identified.

Flat. Most subjects were in Category 3 (arms extended) of five categories for the use of the arms in flight at the pretest. While the control group regressed in the use of the arms in flight, a slight improvement was identified for the direct instruction group. No change in this component was identified for the environmental design group.

A large majority of subjects were in Category 3 (maintained lean) for the use of the trunk during flight which was the highest category identified in this study. While the control group again showed some regression the experimental groups improved slightly in this component.

Swamp. A similar picture to the flat mat condition was identified for the trunk in flight in the swamp testing condition. While the majority of subjects were in the highest Category 3 (maintained lean), the control group regressed at the posttest and the experimental groups brought almost all of the subjects in these groups to the highest category.

Most subjects were in Category 2 (partial tuck) at the pretest for the use of the legs in the flight phase of the jump. At the posttest the control group showed little change, while the experimental groups moved most subjects to Category 3 (full tuck), which was the highest category. The environmental group demonstrated more positive change in this component than the direct instruction group.

\section{Product Data: Retention}

Retention scores for the distance jumped were obtained on 75 of the original subjects. Subject mortality was primarily due to a change in school over the summer. Loss of subjects appeared to occur randomly over age, gender, and skill level within each group. The mean distance jumped for the pretest, posttest, and retention test were analyzed in a $2 \times 3 \times 2 \times 2 \times 3($ Age $\times$ Group $\times$ Skill $\times$ Testing Condition $\times$ Time of Testing) ANOVA with repeated measures on the last two factors. The alpha level was set at .05. Probabilities for tests on the repeated measures factors and their interactions were adjusted using the Huyndt-Feldt correction. Significant main effects were found for age $(F[1,63]=61.20, p<.01)$, skill $(F[2,63]=39.20, p<.01)$, environmental testing condition $(F[1,63]=23.97, p<.01)$, and time $(F[2,126]=36.94, p<.01)$. Seven-year-olds jumped farther overall than 5-year-olds. High and average skilled students jumped farther than lower skilled students.

The other main effects were superseded by the Testing Condition $\times$ Group $\times$ Pretest-Posttest interaction $(F[4,126]=3.37, p<.05)$. The interaction is presented in Figure 2. While all groups improved their performance from the posttest to retention in both testing conditions, the experimental groups did better on the flat mat than they did in the swamp testing condition. This was particularly true for the environmental group.

\section{Discussion and Implications}

Significant changes in both product and process characteristics for the long jump were achieved for both age groups over the 3-day instructional period. The 

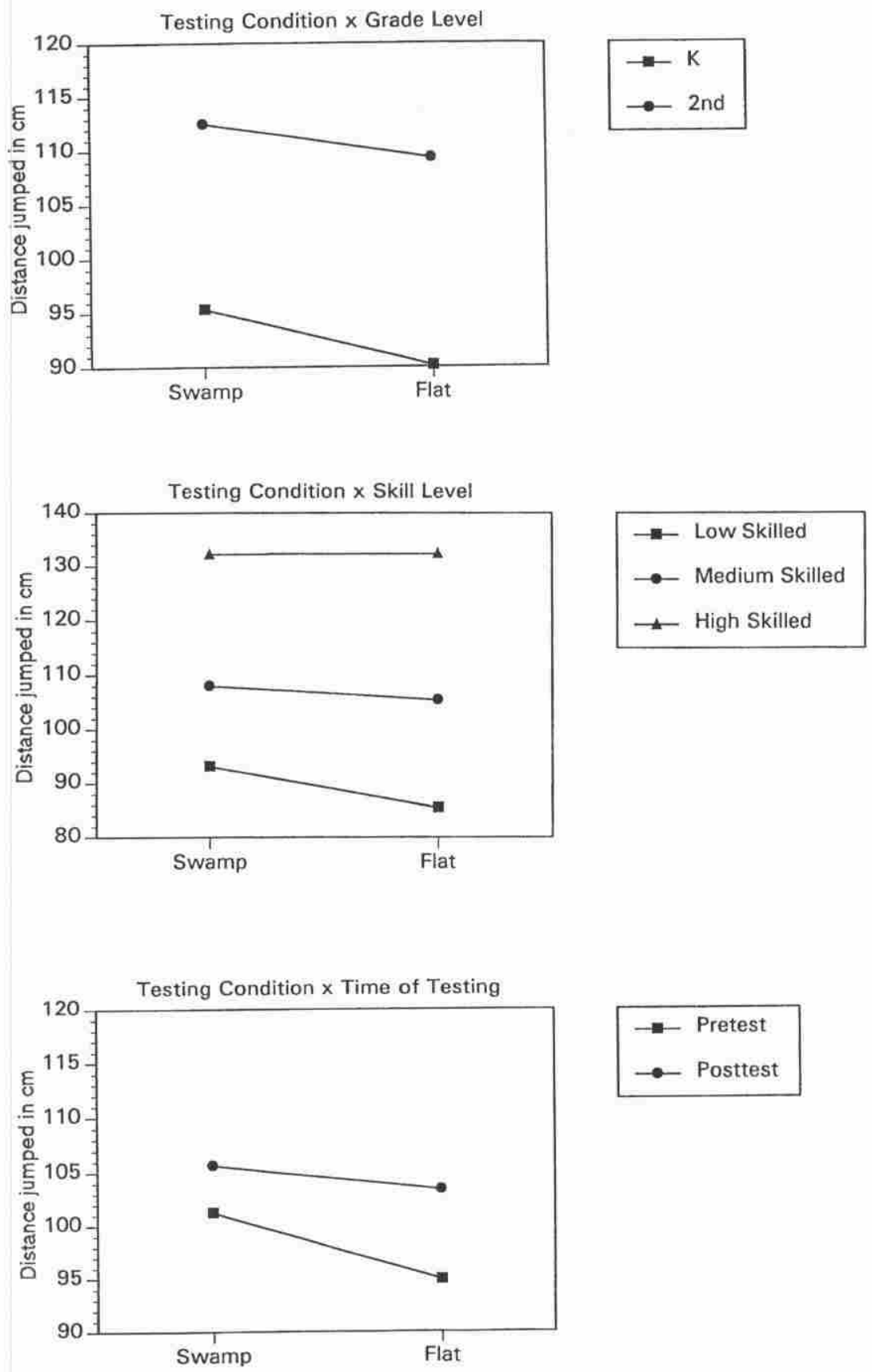

Figure 2 - Pretest, posttest, and retention product scores by testing condition. 
student was used as the unit of analysis in this study. Although an analysis using a large number of groups might have presented a stronger case for the results as is suggested in Silverman and Solmon (1998), a preliminary investigation of differences seems warranted before conducting large scale investigations into potential effects. The significance of this study lies in our understanding the effects of both the testing conditions and the instructional interventions on changes individuals made in their process characteristics as well as the product characteristics of this fundamental skill.

\section{Testing Condition}

The swamp testing condition had a very significant impact on the jump at the pretest and posttest. Subjects jumped farther when tested in the swamp testing condition. This effect was greater for younger subjects and for less skilled subjects. The effect of the swamp testing condition was also stronger at the pretest and seemed to lose its advantage somewhat at the posttest as subjects became more skilled. While the control group continued to perform better in the swamp testing condition on the retention test, the experimental groups actually performed better in the flat mat condition at retention. This may indicate that the swamp testing condition either lost its motivating ability or more probably restricted performance for the subjects who had acquired skill over the instructional period. The idea that the condition that initially produced better performance at the retention test was not as strong as the flat mat condition emphasizes the specificity of the effect of environmental design as an instructional strategy. Students "outgrew" the condition.

Several alternatives exist to explain the regression of the control group. The first is that the pretest and posttest experiences were most likely more motivating for these students. They were brought into the gym for a third time to jump three times. A larger factor perhaps is the notion that variability and potential regression in movement process characteristics is common in the performance of young children. The control group did not have the practice opportunities to work through their changing patterns (Halverson \& Roberton, 1984). Jumping nine times is simply not enough practice at a skill to improve performance. From an instructional standpoint, this finding implies that teachers need to provide sufficient practice to allow students to progress to more advanced patterns. The superficial introduction of a skill without opportunities to more fully develop the skill would be contraindicated and, perhaps in the long run, a waist of instructional time.

In terms of process characteristics the flat mat testing condition produced more change in the use of the arms (preparation, takeoff, and flight) and the trunk in flight. The swamp testing condition produced change in the arms at takeoff and the trunk and legs in flight. The swamp testing condition apparently focused the subjects on attending to the lower half of the body in the action of the jump thereby producing a process characteristic effect in the trunk and legs in flight.

\section{Instructional Groups}

While both instructional groups were significantly different from the control group, they were not significantly different from each other in terms of the amount of change shown in the product score at the retention test. However, there were significant differences in the effects of instruction on the process characteristics from pretest to posttest. A major assumption of instruction is that changes in product scores can come as a result of improving process characteristics of perfor- 
mance. Both groups improved a variety of movement components over several phases of the jump significantly more than the control group, which would support this contention. We also assume that instruction is specific and that different kinds of instruction will produce different effects. This assumption was also supported to a degree. The direct instruction group improved the use of the arms in preparation more than the environmental instruction group. The environmental instruction group improved the tuck of the legs in-flight more than the direct instruction group. Both of these differences make sense from an instructional perspective. It is easier to use direct instruction to effect the preparation phase of a movement. Once a movement such as the long jump is initiated, the speed with which it is performed makes conscious change more difficult. The changes achieved in the tuck of the legs by the environmental instructional group during the execution of the jump are also understandable. Several of the practice conditions of this group involved jumping over things, which should develop the tendency to tuck the legs.

\section{Implications}

On the whole, the environmental instruction did improve performance suggesting that the use of environmental tasks to elicit performance is a viable instructional approach but perhaps should not be used exclusively or indiscriminately. The reduced effects of the (swamp) testing condition with age, skill, and practice can be explained in a variety of ways. The loss of effect may be related to the idea that this condition did not become more challenging (the distance of the swamp stayed the same) even though subjects were told to jump as far as they could over the "swamp." The loss of effect may also be related to motivation issues related to novelty. A third alternative is that the more skilled student already has the pattern and therefore does not benefit from the pattern being elicited by the environment. As students become more skillful, they may be restricted by a testing condition designed to elicit a response which confirms the criticality of the teacher changing and extending task conditions as student ability increases.

The effects of the swamp testing condition were rather specific to the process characteristics, suggesting that when environmental instruction is used, there may be a need to carefully monitor the effects that the environmental condition is having on the process characteristics. Continued investigations into the differential effects of the use of environmental instructional design seem warranted.

An instructional intervention that uses both direct instruction and environmental design at different points in the instruction is also an important concept that needs investigation. Environmental design has potential to be used to initially elicit a movement pattern that is then further refined with direct instruction and with different environments designed specifically for different aspects of the movement. If for instance students are not tucking their legs in the flight of the jump, then providing a condition to elicit the tuck is likely to be more effective than trying to communicate an aspect of performance very difficult to demonstrate or verbally communicate effectively.

The results of this study suggest that teachers should be prepared to design task conditions to elicit movement responses and should learn how to focus on the very specific nature of those environments. Environmental design can be used exclusively in some cases, but it is more likely that instruction will be most effective when teachers learn when to elicit a response and when to approach the teaching 
of skill more directly. The fact that textbooks on teaching physical education devote little or no time to environmental design as a teaching strategy is unfortunate.

\section{References}

Belka, D. (1985). Effects of selected sequencing practices on the catching process of elementary school children. Journal of Teaching in Physical Education, 5, 42-51.

Clark, J., \& Phillips S. (1985). A developmental sequence of the standing broad jump. In J. Clark \& J. Humphrey (Eds.). Motor development-Current selected research (Vol. 1) (pp. 73-85). Princeton, NJ: Princeton Books.

French, K., Rink, J., Rikard, L., Mays, A., Lynn, S., \& Werner, P. (1991). The effect of practice progressions on learning two volleyball skills. Journal of Teaching in Physical Education, 10, 261-275.

French, K., Rink, J., \& Werner, P. (1990). Effects of contextual interference on retention of three volleyball skills. Perceptual Motor Skills, 71, 179-186.

Gusthart, L., \& Springings, E. (1989). Student learning as a measure of teacher effectiveness in physical education. Joumal of Teaching in Physical Education, 8, 298-311.

Hartwell, M.R., \& Serlin, R.C. (1989). A nonparametric test statistic for the general linear model. Journal of Educational Statistics, 14, 351-371.

Herkowitz, J. (1978). Developmental task analysis: The design of movement experiences and evaluation of motor development status. In M. Ridenour (Ed.), Motor development issues and application (pp. 138-164). Princeton, NJ: Princeton Books.

Isaacs, L.D. (1980). Effects of ball size, a ball color, and preferred color on catching by young children. Perceptual and Motor Skills, 1, 583-586.

Kugler, P., Kelso, A., \& Turvey, M. (1980). On the concept of coordinative structures as dissipative structures: I. Theoretical lines of convergence. In G.E. Stelmach and J.E. Requin (Eds.), Tutorials in motor behavior (pp. 3-47). Amsterdam: North Holland.

Logsdon, B., Barrett, K., Ammons, M., Broer, M., Halverson, L., McGee, R., \& Roberton, M. (1984). Physical education for children: A focus of the teaching process. Philadelphia: Lea \& Febiger.

Mallais, J.B. (1984). The effects of color preference on the throwing performance of fourth grade children (Doctoral dissertation, University of Minnesota). Dissertation Abstracts International, 45.

Metzler, M. (1989). A review of research on time in sport pedagogy. Journal of Teaching in Physical Education, 8, 87-103.

Morris, G. (1976). Effects ball and background color have on the catching performance of elementary school children. The Research Quarterly, 4, 409-416.

National Association for Sport and Physical Education (1995). Moving into the future: National standards for physical education. Reston, VA: Author.

National Association for Sport and Physical Education (1992). The Physically Educated Person. Reston, VA: Author.

Newell, K. (1986). Constraints on the development of coordination. In M.G. Wade and H.T.A. Whiting (Eds.), Motor development in children: Aspects of coordination and control (pp. 341-360). The Hague, The Netherlands: Nijhoff.

Payne, V., \& Isaacs, L. (1991). Human motor development: A lifespan approach. Mountain View, CA: Mayfield.

Rink, J., French, K., Werner, P., Lynn, S., \& Mays, A. (1992). The influence of content development on the effectiveness of instruction. Jounnal of Teaching in Physical Education, 11, 138-149. 
Rink, J. (1998). Teaching physical education for learning. Boston: W.C. Brown-McGrawHill.

Roberton, M.A. (1978). Longitudinal evidence for developmental stages in the forceful overarm throw. Journal of Human Movement Studies, 4, 167-175.

Roberton, M.A., \& Halverson, L. E. (1984). Developing children: Their changing movement: A guide for teachers. Philadelphia: Lea and Febiger.

Sawilowsky, S.C. (1990). Nonparametric tests of interaction in experimental design. Review of Educational Research, 60, 91-126.

Siedentop, D., Herkowitz, J., \& Rink, J. (1984). Elementary physical education Methods. Englewood Cliffs, NJ: Prentice-Hall.

Silverman, S. (1991). Research on teaching in physical education: Review and commentary. Research Quarterly for Exercise and Sport, 62, 352-364.

Strohmeyer, H., Williams, K., \& Schaub-George, D. (1991). Developmental sequences for catching a small ball: A prelongitudinal screening. Research Quarterly for Exercise and Sport, 62, 257-266.

Werner, P., \& Rink, J. (1988). Case studies of teacher effectiveness in physical education. Journal of Teaching in Physical Education, 4, 280-297.

\section{Appendix: Developmental Sequences for the Standing Long Jump: Component Approach}

\section{Preparation Phase (addition)}

\section{Leg Action Component}

Step 1: Minimal Flexion. Hips and knees flex greater than $110^{\circ}$ (angle of hip and knees).

Step 2: Some Flexion. Hips and knees flex to $70-110^{\circ}$.

Step 3: Appropriate Flexion. Hips and knees flex to $50-70^{\circ}$.

\section{Trunk Action Component}

Step 1: Delayed Crouch Position. Starts from a crouch position but delays action (prolonged).

Step 2: Arm Pumping. Uses continuous arm pumping action prior to takeoff (two pumps or more plus takeoff).

Step 3: From Stand to Immediate Crouch. Starts from stand and moves into crouch just prior to takeoff (continuous).

\section{Arm Action Component}

Step 1: Arms Down or Inactive. Not parallel or above trunk if in crouch position.

Step 2: Arms Aligned With Flexed Hips.

Step 3: Arms Above Flexed Hips. 


\section{Takeoff Phase}

\section{Leg Action Component}

Step 1: Fall and Catch. The weight is shifted forward. The knee and ankle are held in flexion or extend slightly as gravity rotates the body over the balls of the feet. Takeoff occurs when the toes are pulled from the surface in preparation for the landing "catch."

Step 2: Two-Footed Takeoff, Partial Extension. Both feet leave the ground symmetrically, but the hips, knees, and (or) ankles do not reach full extension by takeoff.

Step 3: Two-Footed Takeoff, Full Extension. Both feet leave the ground symmetrically with the hips, knees, and ankles fully extended by takeoff.

\section{Trunk Action Component}

Step 1: Slight Lean, Head Back. The trunk leans forward less than $30^{\circ}$ from the vertical. The neck is hyperextended.

Step 2: Slight Lean, Head Aligned. The trunk leans forward less than $30^{\circ}$ with the neck flexed or aligned with the trunk at takeoff.

Step 3: Forward lean, Chin Tucked. The trunk is inclined forward $30^{\circ}$ or more (with the vertical) at takeoff with the neck flexed.

Step 4: Forward Lean, Head Aligned. The trunk is inclined forward $30^{\circ}$ or more. The neck is aligned with the trunk or slightly extended.

\section{Arm Action Component}

Step 1: Arms Inactive. The arms are held at the side with the elbows flexed. Arm movement, if any, is inconsistent and random. takeoff.

Step 2: Winging Arms. The arms extended backward in a winging posture at

Step 3: Arms Abducted. The arms are abducted about $90^{\circ}$ with the elbows often flexed in a high or middle guard position.

Step 4: Arms Forward, Partial Stretch. The arms flex forward and upward with minimal abduction, reaching incomplete extension overhead by takeoff.

Step 5: Arms Forward, Full Stretch. The arms flex forward and upward with minimal abduction, reaching full extension overhead by takeoff.

\section{Flight and Landing Phase}

\section{Leg Action Component}

Step 1: Minimal Tuck. The thigh is carried in flight more than $45^{\circ}$ below the horizontal. The legs may assume either symmetrical or asymmetrical configuration during flight, resulting in one- or two-footed landings.

Step 2: Partial Tuck. During flight, the hips and knees flex synchronously. The thigh approaches a $20-35^{\circ}$ angle below the horizontal. The knees then extend for a two-footed landing.

Step 3: Full Tuck. During flight, flexion of both knees precedes hip flexion. The hips then flex, bringing the thighs to the horizontal. The knees then extend, reaching forward to a two-footed landing. 


\section{Trunk Action Component}

Step 1: Slight Lean. During flight, the trunk maintains its forward inclination of less than $30^{\circ}$, then flexes for landing.

Step 2: Corrected Lean. The trunk corrects its forward lean of $30^{\circ}$ or more by hyperextending. It then flexes forward for landing.

Step 3: Maintained Lean. The trunk maintains the forward lean of $30^{\circ}$ or more from takeoff to mid-flight, then flexes forward for landing.

\section{Arm Action Component (revision)}

Step 1: Arms Winging. In two-footed takeoff jumps, the shoulders may retract while the arms extend backwards (winging) during flight. They move forward (parachuting) during landing.

Step 2: Arms Held. Arms maintain high guard or middle guard position in relation to the trunk. Held position.

Step 3: Arms Extended. From high guard or middle guard position, the arms extend farther out to the side.

Step 4: Arms Forward. From high guard or middle guard position, the arms move forward and (or) drop down.

Step 5: Arms Overhead. During flight, the arms are held overhead. In middle flight, the arms lower from the overhead position, reaching forward at landing.

\section{Acknowledgment}

The authors would like to acknowledge the statistical help of Karen French in the Department of Physical Education and Mike Seaman in Educational Research at the University of South Carolina. 